\title{
Nonlinear Dynamics of Jeffcott Rotor System with Rub-Impact Fault Yazhe Chen ${ }^{1, a}$ Liqun Liu ${ }^{1, b}$ Yang Liu ${ }^{1, a}$ and Bangchun Wen ${ }^{1, c}$
} ${ }^{1}$ School of Mechanical Engineering \& Automation, Northeastern University, Shenyang, Liaoning,
PR China 110004

ayzhchen@mail.neu.edu.cn, ${ }^{b}$ liuliqun253@163.com, 'bcwen1930@vip.sina.com

Key words: Rotor model, Rub-impact fault, Nonlinear finite element method, Dynamics

\begin{abstract}
The rub-impact fault of Jeffcott rotor system which is generally made of an elastic shaft with supported by two bearings at ends and a lumped mass at the mid-span of shaft is the main research subject of this paper. The mechanical model and finite element model of a lump mass at the mid-span of shaft is set up. The dynamics of it are studied by nonlinear finite element method under the rub-impact conditions, and by investigating the effects of stiffness of stator and the clearance between rotor-stator. From the study results, use finite element method to study the rotor system failure problem is intuitive and convenient, high accuracy, high reliability, can be widely applied.
\end{abstract}

\section{Introduction}

As the demand of high speed and high efficiency for rotating machinery, the gap between rotor and stator is more and more small, which leads to rub-impact fault happens very often between the rotor and stator. Rub-impact is an often happened serious fault in rotating machinery. When rub-impact happens firstly, it can be observed local rub-impact of the rotor, in a rotation period, rub-impact between the stator and rotor may contact one, two or more. Evolution of local rub-impact can gradually lead to the whole week rub-impact, serious rub-impact can also cause system does not work normally [1]. Therefore, for rotating machinery rub-impact the evaluation of operation status and early diagnosis, research on nonlinear vibration of rub-impact fault is very important.

This paper mainly studies rub-impact fault of rotor model that support on both ends and the concentration mass in the middle based on Jeffcott [2].

\section{The Model of Rotor System with Rub-Impact}

Finite Element Modeling of the Rotor System. Take the simplified rigid symmetric supporting rotor-bearing system including rub-impact fault as the study object [3], as shown in Figure 1(a). On both ends of the rotor with sliding bearing support, $O_{1}$ is the geometric centre of bearing bush, $O_{2}$ is the geometric centre of rotor, $O_{3}$ is the mass centre of the rotor, $k_{c}$ is the stator stiffness, $k$ is the elastic bearing stiffness, $c_{1}$ is the damping coefficient of rotor in bearing place, $c_{2}$ is the damping coefficient of rotor in disc place. $m_{1}$ is the concentration mass of the rotor in bearing, $m_{2}$ is the equivalent concentration mass in disc place, between rotor disc and bearing is no mass elastic axis.

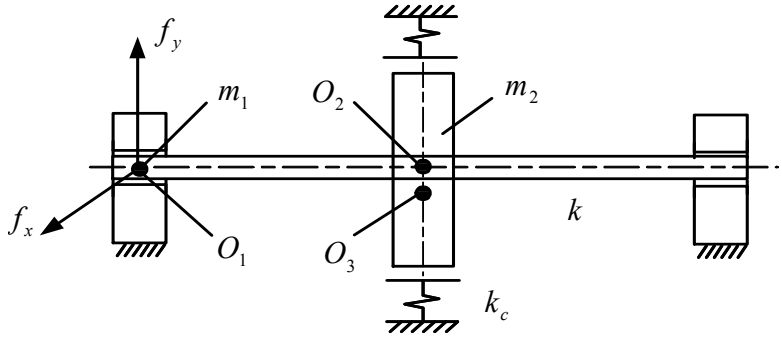

(a) Rub-impact rotor diagram

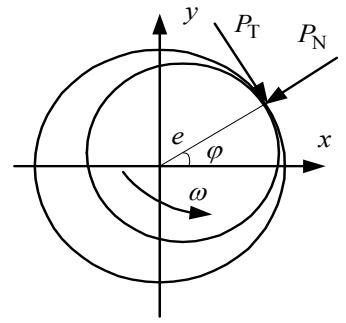

(b) Local rub-impact model

Fig. 1. Mechanical modelof rub-impact rotor-bearing system 
Without considering the heating effect of the friction, and assumes rotor and stator is elastic collision, rub-impact is local rub-impact, rotor local rub-impact force model as shown in Figure 1(b). $P_{N}$ is radial crash force, $P_{T}$ is tangential friction, $\varphi$ is the angle that between the normal direction of rub-impact point and $x$ axis. $\omega$ is the rotor rotation velocity, $e$ is the rotor axis displacement.

Figure 2 is the finite element model of the rotor after discrete, the little black dots represent node, big black circles represent focus on quality, number represents node number, two spring damping is to simulate bearing role.

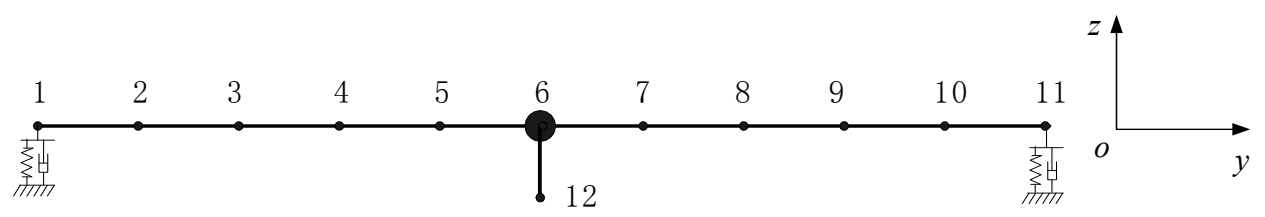

Fig. 2. The finite element model of the single plate rotor

Rub-Impact Force Expression. Assume the stator radial deformation is linear, $k_{c}$ is the stator radial stiffness, the friction between rotor and stator conforms to the Coulomb Friction Law, friction coefficient is $f$, namely, the friction and positive pressure acts on contact surface is directly proportional, and set the gap between rotor and stator is $\delta$, then the crash force for friction force[4] are respectively:

$$
\left\{\begin{array}{l}
P_{N}=(e-\delta) k \\
P_{T}=f \cdot P_{N}
\end{array} \quad(e \geq \delta),\right.
$$

where $e$ is radial displacement of rotor,

$$
e=\sqrt{x^{2}+y^{2}} \geq \delta \text {. }
$$

Rub-impact force of the $x, y$ direction components are as follows in the $x$ - $y$ coordinate system:

$$
\left\{\begin{array}{l}
P_{x} \\
P_{y}
\end{array}\right\}=\left[\begin{array}{ll}
-\cos \varphi & \sin \varphi \\
-\sin \varphi & -\cos \varphi
\end{array}\right]\left\{\begin{array}{l}
P_{N} \\
P_{T}
\end{array}\right\},
$$

Eq.(1) and Eq.(2) are substituted in Eq.(5), get:

$\left\{\begin{array}{l}P_{x} \\ P_{y}\end{array}\right\}=-\frac{(e-\delta) k_{c}}{e}\left[\begin{array}{cc}1 & -f \\ f & 1\end{array}\right]\left\{\begin{array}{l}x \\ y\end{array}\right\} \quad(e \geq \delta)$.

Assume $\hat{x}=x / c, \hat{y}=y / c, c$ is bearing gap, then rub-impact in the direction of $x-y$ relative to non-dimensional displacement $\hat{x}, \hat{y}$ of expression for:

$$
\begin{gathered}
\left\{\begin{array}{l}
P_{\hat{x}} \\
P_{\hat{y}}
\end{array}\right\}=-\frac{c(e-\delta) k_{c}}{e}\left[\begin{array}{cc}
1 & -f \\
f & 1
\end{array}\right]\left\{\begin{array}{l}
\hat{x} \\
\hat{y}
\end{array}\right\} \quad(e \geq \delta) \quad(e \geq \delta) . \\
P_{x}=P_{y}=0
\end{gathered}
$$

Differential Equation of Rub-Impact Rotor System. It assumes the radial displacement of turntable place is $x_{1}, y_{1}$; the radial displacement of rotor left $x_{2}, y_{2}$. It assumes $\tilde{x}_{1}=x_{1} / c$, $\tilde{y}_{1}=y_{1} / c, \tilde{x}_{2}=x_{2} / c, \tilde{y}_{2}=y_{2} / c$. Then systematic dimensionless kinematics differential equation can be expressed as (where still use $x_{1}$ express $\tilde{x}_{1}, x_{2}$ express $\tilde{x}_{2}, y_{1}$ express $\tilde{y}_{1}, y_{2}$ express $\tilde{y}_{2}$ ):

$$
\left\{\begin{array}{l}
\ddot{x}_{1}=-\frac{c_{1}}{\omega m_{1}} \dot{x}_{1}-\frac{k}{\omega^{2} m_{1}}\left(x_{1}-x_{2}\right)+\frac{\delta P}{c \omega^{2} m_{1}} f_{x}\left(x_{1}, y_{1}, \dot{x}_{1}, \dot{y}_{1}\right)+\tilde{b} \cos \tau \\
\ddot{y}_{1}=-\frac{c_{1}}{\omega m_{1}} \dot{y}_{1}-\frac{k}{\omega^{2} m_{1}}\left(y_{1}-y_{2}\right)+\frac{\delta P}{c \omega^{2} m_{1}} f_{y}\left(x_{1}, y_{1}, \dot{x}_{1}, \dot{y}_{1}\right)+\widetilde{b} \sin \tau-G \\
\ddot{x}_{2}=-\frac{c_{2}}{\omega m_{2}} \dot{x}_{2}-\frac{2 k}{\omega^{2} m_{2}}\left(x_{2}-x_{1}\right)+\frac{P_{x}\left(x_{2}, y_{2}\right)}{c m_{2} \omega^{2}} \\
\ddot{y}_{2}=-\frac{c_{2}}{\omega m_{2}} \dot{y}_{2}-\frac{2 k}{\omega^{2} m_{2}}\left(y_{2}-y_{1}\right)+\frac{P_{y}\left(x_{2}, y_{2}\right)}{c m_{2} \omega^{2}}-G
\end{array},\right.
$$


where, $f_{x}, f_{y}$ are dimensionless nonlinear oil film force, $f_{x}=\frac{F_{x}}{\delta P}, f_{y}=\frac{F_{y}}{\delta P}, F_{x}, F_{y}$ is nonlinear oil film force that sliding bearing acts on the axis in figure $1, P_{x}\left(x_{2}, y_{2}\right), P_{y}\left(x_{2}, y_{2}\right)$ is the component rub-impact force of rotor system in $\mathrm{x}, \mathrm{y}$ direction. $\delta$ is Sommerfeld[5] Correction coefficient, and its mathematical expression is $\delta=\frac{\mu \omega R L}{P}\left(\frac{R}{c}\right)^{2}\left(\frac{L}{2 R}\right)^{2}, c$ is the average oil film thickness, $\mu$ is lubricating oil viscosity, $P$ is the weight half rotor disc, $L$ is the bearing length, $R$ is the bearing radius, $\mathrm{G}$ is the dimensionless external applied load, $\widetilde{b}=b / c, \tau$ is the dimensionless time, $\tau=\omega t$.

\section{The Dynamic Characteristics and Bifurcation Behavior Caused by Parameter Changes}

In order to further study the rub-impact of rotor system, we need to know that system show the dynamic behaviors when parameters changing. The periodic solutions of nonlinear system have various research methods, but numerical method is still the most effective tool of researching system quasi periodicity and chaos phenomena. In view of the oil film bearing force has strong nonlinear characteristics, this article uses the Runge-Kutta[5] method to solve differential equations.

The Influence of Rub-Impact Stiffness. The basic parameters of rotor system are: $e=0.05 \mathrm{~mm}$, $m_{1}=4.0 \mathrm{~kg}, \quad m_{1}=32.1 \mathrm{~kg}, R=25 \mathrm{~mm}, L=12 \mathrm{~mm}, c=0.11 \mathrm{~mm}, \mu=0.018 \mathrm{~Pa} \cdot \mathrm{s}, \omega=900 \mathrm{~Hz}$, $f=0.1, \quad c_{1}=1050 \mathrm{~N} \cdot \mathrm{s} / \mathrm{m}, \quad c_{1}=2100 \mathrm{~N} \cdot \mathrm{s} / \mathrm{m}, k=2.5 \times 10^{7} \mathrm{~N} \cdot \mathrm{m}^{-1}$, the different stator stiffness are analyzed in this paper.

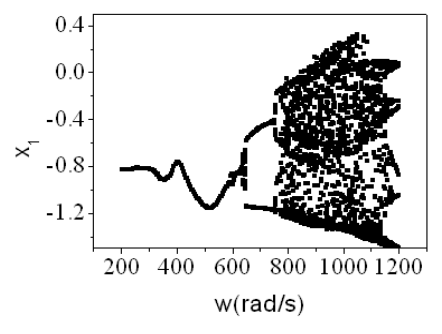

(a) $k_{c}=3.0 \times 10^{6} \mathrm{~N} \cdot \mathrm{m}^{-1}$

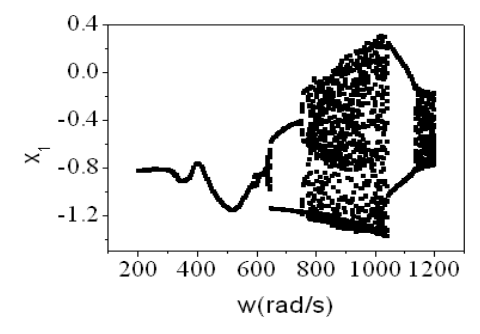

(b) $k_{c}=3.5 \times 10^{6} \mathrm{~N} \cdot \mathrm{m}^{-1}$

Fig. 3. The bifurcation figure of different stator stiffness
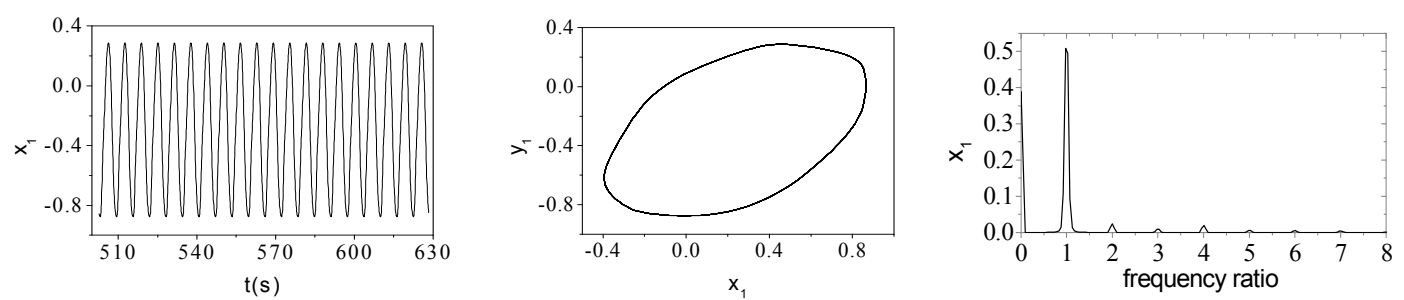

(a) The time waveform figure (b) The axis path chart (c) The amplitude spectrum diagram
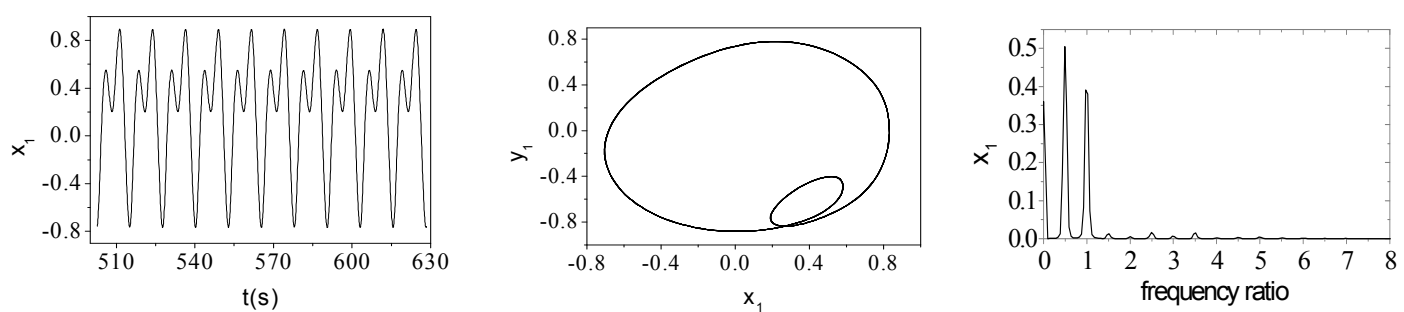

(a) The time waveform figure (b) The axis path chart (c) The amplitude spectrum diagram Fig. 4. The time waveform, axis path and amplitude spectrum diagram when $k_{c}=3.0 \times 10^{6} \mathrm{~N} \cdot \mathrm{m}^{-1}$

Figure 3(a) is the bifurcation diagram when stator stiffness $k_{c}=3.0 \times 10^{6} \mathrm{~N} \cdot \mathrm{m}^{-1}$ integral 1000 steps, Figure 4(a)-(c) and (d)-(f) are the time waveform figure, axis path chart and amplitude spectrum diagram when stator stiffness is $k_{c}=3.0 \times 10^{6} \mathrm{~N} \cdot \mathrm{m}^{-1}$, before and after system bifurcation 
speed respectively are $\omega=500 \mathrm{rad} / \mathrm{s}$ and $\omega=700 \mathrm{rad} / \mathrm{s}$, the figure can clearly see, when $\omega=500 \mathrm{rad} / \mathrm{s}$ the axis path of the response system is a closed circle, from amplitude spectrum chart can be seen only the same frequency components with speed frequency, it can be known the system sport is the same frequency cycle exercise; while system rotate speed $\omega=700 \mathrm{rad} / \mathrm{s}$, there is an obvious secondary peak in time waveform, because of rub-impact the axis motion peak appears reverse precession, the axis path of the system response is two mutually nested closed circle, from amplitude spectrum chart can be seen that system exists half frequency components in addition to the same frequency with rotate speed, we know system motion is period doubling movement.

Figure 3(b) is the bifurcation diagram when stator stiffness $k_{c}=3.5 \times 10^{6} \mathrm{~N} \cdot \mathrm{m}^{-1}$ integral 1000 steps, Figure 5(a)-(c) and (d)-(f) are the time waveform figure, axis path chart and amplitude spectrum diagram before and after system bifurcation speed respectively are $\omega=500 \mathrm{rad} / \mathrm{s}$ and $\omega=700 \mathrm{rad} / \mathrm{s}$. From the figure it can be seen clearly that has hardly difference compared with stator stiffness $k_{c}=3.0 \times 10^{6} \mathrm{~N} \cdot \mathrm{m}^{-1}$ related figure. But the bifurcation diagram has obvious change, and appears inverse bifurcation phenomenon, it illustrates with continuing to increase $k_{c}$, rub-impact force increase and close to and more than oil film force.
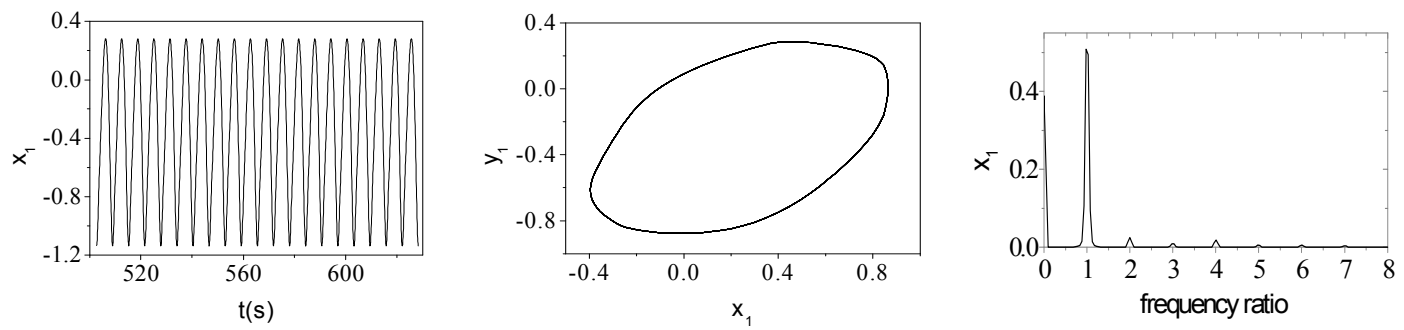

(a) The time waveform figure (b) The axis path chart (c) The amplitude spectrum diagram
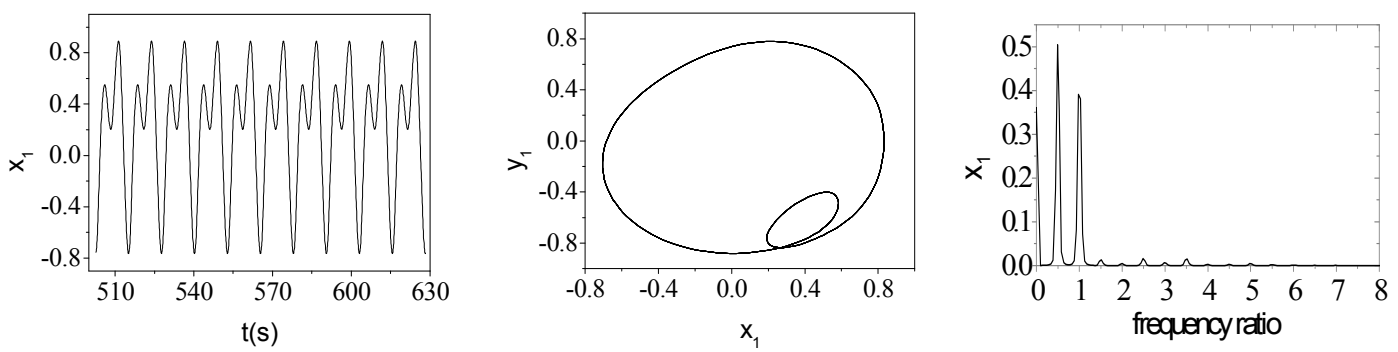

(a) The time waveform figure (b) The axis path chart (c) The amplitude spectrum diagram Fig. 5. The time waveform, axis path and amplitude spectrum diagram when $k_{c}=3.5 \times 10^{6} \mathrm{~N} \cdot \mathrm{m}^{-1}$

The Influence of Rub-Impact Gap. Set stator stiffness $k_{c}=3.5 \times 10^{6} \mathrm{~N} \cdot \mathrm{m}^{-1}$, other parameters have the same with above. Figure 6(a) is the bifurcation diagram of rub-impact gap $\delta=1.0 \mathrm{~mm}$, Figure 7(a)-(c) and (d)-(f) are the time waveform figure, axis path chart and amplitude spectrum diagram before and after system bifurcation speed respectively are $\omega=500 \mathrm{rad} / \mathrm{s}$ and $\omega=700 \mathrm{rad} / \mathrm{s}$. The figure can clearly see, when $\omega=500 \mathrm{rad} / \mathrm{s}$ the axis path of the response system is a closed circle, from amplitude spectrum chart can be seen only the same frequency components with speed frequency, it can be known the system sport is the same frequency cycle exercise; while system rotate speed $\omega=700 \mathrm{rad} / \mathrm{s}$, there is an obvious secondary peak in time waveform, because of rub-impact the axis motion peak appears reverse precession, the axis path of the system response is two mutually nested closed circle, from amplitude spectrum chart can be seen that system exists half frequency components in addition to the same frequency with rotate speed, we know system motion is period doubling movement. These features have the same with above. 


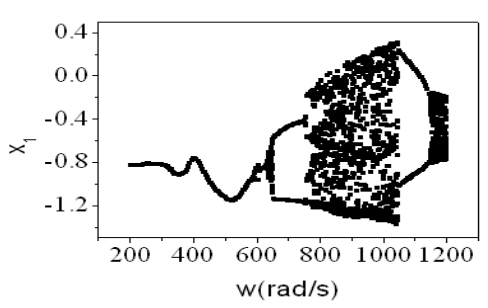

(a) Rub-impact gap $\delta=1.0 \mathrm{~mm}$

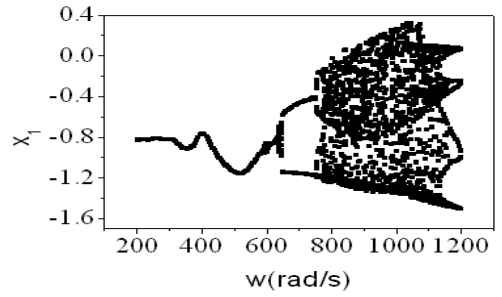

(b) Rub-impact gap $\delta=1.2 \mathrm{~mm}$ Fig. 6. The bifurcation diagram of different rub-impact gap

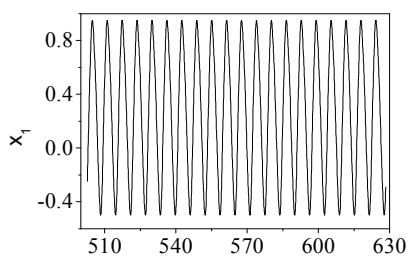

$\mathrm{t}(\mathrm{s})$

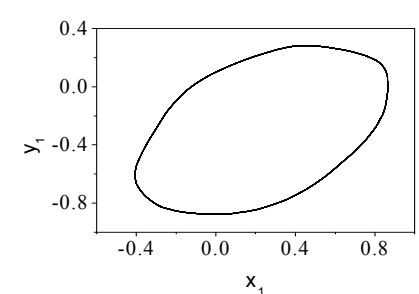

(b) The axis path chart

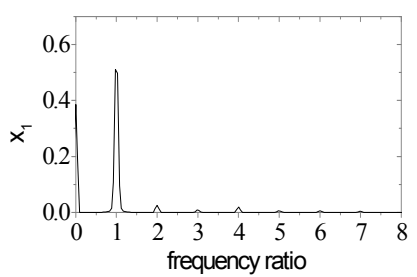

(c) The amplitude spectrum diagram

(a) The time waveform figure
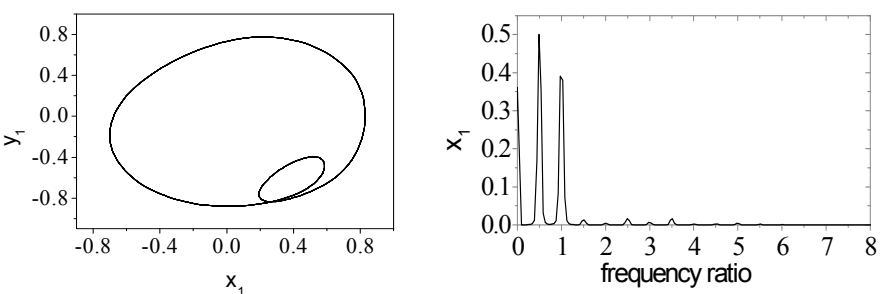

(a) The time waveform figure

(b) The axis path chart

(c) The amplitude spectrum diagram

Fig. 7. The time waveform figure, axis path chart and amplitude spectrum diagram of $\delta=1.0 \mathrm{~mm}$

Figure 3(b) is the bifurcation diagram of rub-impact gap $\delta=1.1 \mathrm{~mm}$, Figure 5(a)-(c) and (d)-(f) are the time waveform figure, axis path chart and amplitude spectrum diagram before and after system bifurcation speed respectively are $\omega=500 \mathrm{rad} / \mathrm{s}$ and $\omega=700 \mathrm{rad} / \mathrm{s}$.

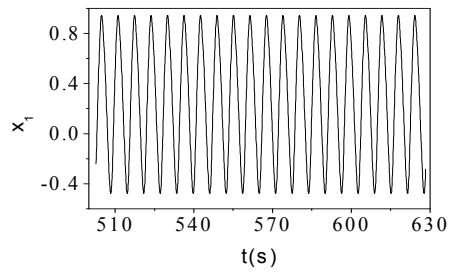

(a) The time waveform figure

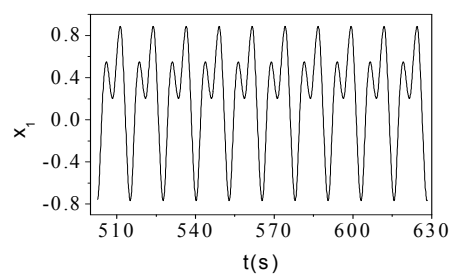

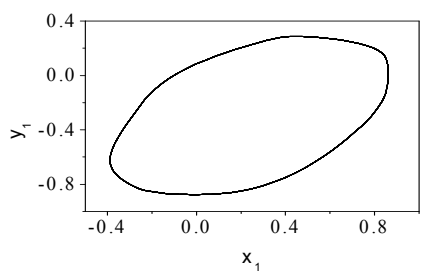

(b) The axis path chart

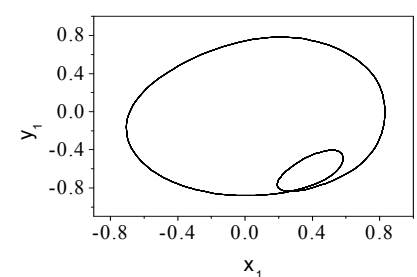

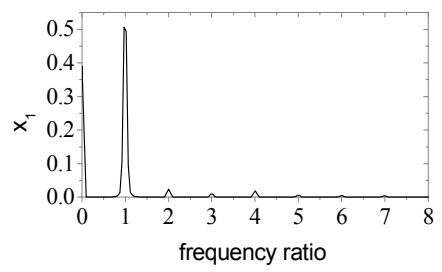

(c) The amplitude spectrum diagram

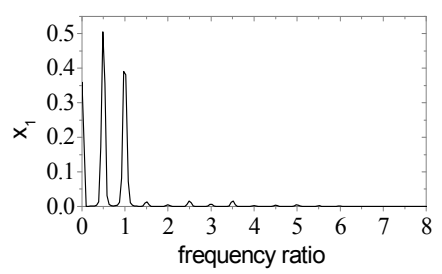

$\begin{array}{lll}\text { (a) The time waveform figure } & \text { (b) The axis path chart } & \text { (c) The amplitude spectrum diagram }\end{array}$ Fig. 8. The time waveform figure, axis path chart and amplitude spectrum diagram of $\delta=1.2 \mathrm{~mm}$

Figure $6(\mathrm{~b})$ is the bifurcation diagram of rub-impact gap $\delta=1.2 \mathrm{~mm}$, Figure $8(\mathrm{a})$-(c) and (d)-(f) are the time waveform figure, axis path chart and amplitude spectrum diagram before and after system bifurcation speed respectively are $\omega=500 \mathrm{rad} / \mathrm{s}$ and $\omega=700 \mathrm{rad} / \mathrm{s}$.

This paper studies some situations of rub-impact gap $\delta=0.4 \mathrm{~mm}, \delta=0.6 \mathrm{~mm}, \delta=0.8 \mathrm{~mm}$, and finds the time waveform figure, axis path chart and amplitude spectrum diagram of system have similarities to $\delta=1.0 \mathrm{~mm}, \delta=1.1 \mathrm{~mm}, \delta=1.2 \mathrm{~mm}$. But in addition to $\delta=0.8 \mathrm{~mm}$, the bifurcation diagrams of other two rub-impact gaps are different, Figure 9 is the bifurcation diagrams of 
$\delta=0.4 \mathrm{~mm}$ and $\delta=0.6 \mathrm{~mm}$. Instability rotor speed in Figure 9 (a) is $600 \mathrm{rad} / \mathrm{s}$, instability rotor speed in Figure $9(\mathrm{~b})$ is $660 \mathrm{rad} / \mathrm{s}$, while $\delta=0.8 \mathrm{~mm}$, system instability rotor speed is $592 \mathrm{rad} / \mathrm{s}$, at this time the excessive rub-impact gap makes rub-impact no longer occur or occur after oil film vortex, so instability speed remain unchanged.

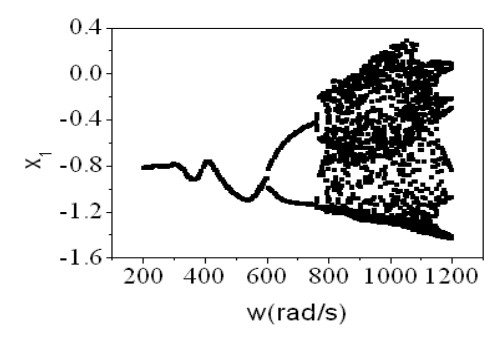

(a) $\delta=0.6 \mathrm{~mm}$

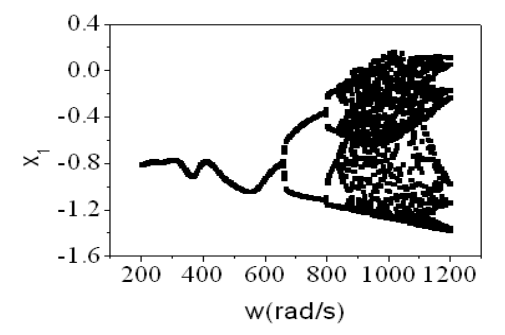

(b) $\delta=0.4 \mathrm{~mm}$

Fig. 9. The bifurcation diagram of rub-impact gap $\delta=0.6 \mathrm{~mm}, \delta=0.4 \mathrm{~mm}$

\section{Conclusions}

This paper studies the dynamic characteristics of the lumped mass rotor, according to the calculated data and graph we can get the following conclusion:

(1) The influence of rub-impact stiffness: the axis path of the system response before the bifurcation is a closed circle, from amplitude spectrum chart can be seen only the same frequency components with speed frequency, it can be known the system sport is the same frequency cycle exercise; there is an obvious secondary peak in time waveform after the bifurcation, because of rub-impact the axis motion peak appears reverse precession, the axis path of the system response is two mutually nested closed circle, from amplitude spectrum chart can be seen that system exists half frequency components in addition to the same frequency with rotate speed, we know system motion is period doubling movement. When the stator stiffness reaches a certain range, rub-impact force becomes the dominant factors in the movement, with this range the system response has not changed much.

(2) The influence of rub-impact gap: the axis path of the system response before the bifurcation is a closed circle too, from amplitude spectrum chart can be seen only the same frequency components with speed frequency, it can be known the system sport is the same frequency cycle exercise; there is an obvious secondary peak in time waveform after the bifurcation, because of rub-impact the axis motion peak appears reverse precession, the axis path of the system response is two mutually nested closed circle, from amplitude spectrum chart can be seen that system exists half frequency components in addition to the same frequency with rotate speed, we know system motion is period doubling movement. When rub-impact gap reaches to a certain value, instability rotor speed of the system basic stability above a certain value, at this time the excessive rub-impact gap makes rub-impact no longer occur or occur after oil film vortex, so instability speed remain unchanged.

\section{References}

[1] Z. P. Li: Study on some nonlinear problem of fault rotor system, Northeastern University 2002

[2] H. H. Jeffcott, The lateral vibration of loaded shafts in the neighbourhood of a whirling speed-the effect of want of balance, Philosophical Magazine 6(1919) 304 314.

[3] Y. Z. Chen: Nonlinear dynamic analysis of rotor with rub-impact fault, Northeastern University 2006.

[4] B. C. Wen, X. H. Wu, Q. Ding, Q. K. Han, Theory and test of fault rotating machinery nonlinear dynamics, first ed., Science Press, Beijing, 2004.

[5] B. C. Wen, Y. N. Li, Q. K. Han, Analysis method and the engineering application of nonlinear vibration theory, first ed., Northeastern University Press, Shenyang, 2001. 